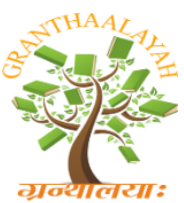
\author{
GRANTHAALAYAH \\ A knowledge Repository
}

INTERNATIONAL JOURNAL OF RESEARCH -

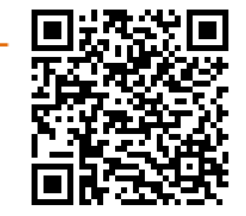

Science

\title{
STUDIES ON MOSQUITO REPELLENT ACTIVITY OF CYMBOPOGON CITRATUS (LEMON GRASS) USING HUMAN VOLUNTEERS
}

\author{
Ukpong, Iniodu George ${ }^{* 1}$, Ettah, Hannah Edim ${ }^{2}$, Eshuong, Emmanuel Edet ${ }^{3}$ \\ *1, 2,3 Department of Biological Sciences, Cross River University of Technology, Calabar,
} Nigeria

DOI: https://doi.org/10.29121/granthaalayah.v4.i12.2016.2391

\begin{abstract}
Background: Safety concerns over the use of chemical-based pesticides are provoking intense studies and application of bio-pesticides in disease control and agriculture. Aim: This qualitative study was aimed at testing the repellent efficacy; and suitability of Cymbopogon citratus (Lemongrass) for the development of natural product-based mosquito repellent. Method: Cymbopogon oil $(75 \mathrm{ml})$ was extracted from $200 \mathrm{~g}$ of fresh Lemongrass leaves using Soxhlet method with n-Hexane as solvent. Human volunteers were topically treated with $2 \mathrm{ml}$ and $6 \mathrm{ml}$ of Cymbopogon oil applied on exposed areas of the body at night; and observed for 4hrs 30mins. Direct test on mosquitoes in captivity was conducted using a 2-chambered insect box treated with $4 \mathrm{ml}$ of oil in one chamber. Results: Human subjects were free from mosquito bites for 3 hours. Mosquitoes in captivity exhibited active movement away from oil-treated chamber of the box within the first minute of application; $43 \%$ repellency and 100\% mortality were recorded after 18 minutes. Conclusion: Findings suggest that Cymbopogon citratus extracts could be used for the production of potent chemical-free and safe mosquito repellent and insecticide for vector control in the fight against malaria and other mosquito-vectored diseases. However further studies and qualitative analyses are necessary to determine suitable concentrations for human topical application.
\end{abstract}

Keywords: Cymbopogon Citratus; Essential Oil; Repellent; Mosquito; Human Volunteers; Calabar.

Cite This Article: Ukpong, Iniodu George, Ettah, Hannah Edim, and Eshuong, Emmanuel Edet. (2016). "STUDIES ON MOSQUITO REPELLENT ACTIVITY OF CYMBOPOGON CITRATUS (LEMON GRASS) USING HUMAN VOLUNTEERS." International Journal of Research - Granthaalayah, 4(12), 41-47. 10.29121/granthaalayah.v4.i12.2016.2391.

\section{Introduction}

Mosquitoes have been implicated in the transmission of very debilitating and deadly diseases to humans; such as malaria, filariasis, dengue fever and yellow fever. Little wonder that the quest 
for the control of this arthropod vector have remained a major focus in disease control / eradication programmes; which could be traced back to the earliest global malaria eradication effort of residual insecticidal campaign [1]. Apart from the use of insecticides for residual house spraying and other basic strategies targeted at the vector, the fight against mosquito-borne infections also engages preventive measures to avoid or reduce vector-man contact, such as avoiding places of high mosquito densities, wearing protective clothing outdoors, use of bed and window nets, and use of mosquito repellents, etc. These formed part of the Global Malaria Control Strategy [2-5]. These have today come to constitute the components of integrated vector control.

Mosquito control has been known among people of many cultures around the globe. A variety of local mosquito control practices have been documented in the past few decades; such as the use of traditional fumigants made from natural products as source of deterrent smoke, e.g. herb smoke in Burundi, [6]; burning of cassava chips and herbs in Ghana [7]; burning of bark of the tree Daniella oliveri in Gambia, [8]; and other such fumigants in Sri Lanka [9]. The use of a paste (Thanaka) derived from Limonia acidissima (the wood apple tree) for skin application as repellent had been reported in Thailand [10][8]. In some parts of Nigeria deterrent smoke from palm kernel shells and dried orange peels serve the purpose. These indicate the long existing use of natural products to control mosquitoes, earlier before the current trend in bio-pesticide use. There is evidence that the use of biological control agents against mosquitoes grew in the beginning of the $20^{\text {th }}$ Century, but reduced with the discovery of the insecticidal properties of Dichlorodiphenyl trichloroethane (DDT) in 1939 [11]. However, the gradual development of resistance by many species of insects, suggested association with human cancers [4] and other public health problems [12], the use of DDT dwindled, even as it was banned in the USA in 1973[13].

Commercially available chemical-based insecticides and repellents are known to contain harmful and poisonous compounds which could pose threats to human health and toxicity to non-target organisms [14]. The repellent efficacy of the chemical N,N-diethyl-3-methylbenzamide (DEET) over other products made it the compound of choice in pesticides [15]. However, concerns of its safety have not ceased to be considered. The effects on human health, aquatic species and the environment have been reviewed [16],[17],[18]. The seeming renewed focus on natural productbased repellents sets to replace hazardous chemical-based products with safe alternatives; hence the concept of green pesticides [19].

Studies have demonstrated the insecticidal effect of plant products, which make them suitable as safe pest control products. Essential oils from a variety of plant species have been used as very effective pest repellents; such as Cymbopogon nardus, Cymbopogon excavatus, Azaradicta indica, Eucalyptus maculata etc. [11]. Etta and others reported the insecticidal property of Ocimum gratissimum extract on wild-caught adult Anopleles mosquitoes [20].

Cymbopogon citratus (Lemon grass) oil has been known as effective insect repellent; its effectiveness in mosquito repellence has also been documented [21],[22]. This study was aimed at testing the mosquito repellent property of Cymbopogon citratus on human volunteers and mosquitoes in captivity, to determine its suitability as natural product-based mosquito repellent. 


\section{Methods}

\section{Extraction of Lemongrass Oil}

Fresh leaves of Cymbopogon. citratus (lemon grass) were sliced and ground. Two hundred grams $(200 \mathrm{~g})$ of ground leaves were placed in a porous thimble, for oil extraction using the Soxhlet extraction method, with n-Hexane solvent. About $75 \mathrm{ml}$ of oil, weighing $36.4 \mathrm{~g}$, was extracted and stored in the refrigerator at $4^{\circ} \mathrm{C}$.

\section{Collection of Mosquito Specimens}

Mosquitoes were collected in an open area using a sieve net and safely transferred into an insect box. This was repeated severally to obtain the desired number of mosquito samples. The mosquitoes were taken to the Biology laboratory, Department of Biological Sciences, Cross River University of Technology, Calabar, and identified as Anopheles species by an entomologist before the test.

Test of Repellent Activity of C. citratus on Human Volunteers

The test was conducted at Cross River University of Technology, Calabar Campus Hostel, Hall 2. Five student volunteers participated in the study; 2 of them applied $2 \mathrm{ml}$ and 2 applied $6 \mathrm{ml}$ of lemon grass oil topically on the legs, arms and head (including the ear), while 1 did not apply oil and was used as control. All volunteers were awake and reading throughout the duration of the experiment in a hostel room where relative abundance of mosquitoes was previously established. The experiment was observed for 4 hours thirty minutes (from 22.00 hours to 02:30 hours). Results recorded included individual observations by each volunteer and the researchers; with respect to mosquito landing attempts/bites, place of bites, number of bites and time interval between bites.

Test for repellent activity of $C$. citratus on mosquitoes in captivity

The laboratory experiment was conducted using an insect box designed with a surface area of $2756 \mathrm{~cm}^{2}$; with an open surface covered with net. The box had two chambers, A (lemon grass oiltreated) and B (untreated), with an opening linking both. A petri dish containing $6 \mathrm{ml}$ of Cymbopogon oil was placed in chamber A; and thirty (30) freshly caught, live mosquitoes were carefully transferred into same chamber of the box. Timed observations of the reaction of mosquitoes were recorded.

\section{Ethical considerations}

Ethical approval for the study was obtained from the Chief Medical Director of the Cross River University of Technology, through the Dean, Student Affairs Division of the University. Informed consent was obtained from all volunteers that participated in the research.

\section{Results}

\section{Repellent Activity of C. citratus on Human Volunteers}

The test volunteers experienced zero mosquito landing attempts and bites until three hours, while the control volunteer had mosquito landings and bites within 2 minutes of the experiment. One volunteer who applied $2 \mathrm{mls}$ of $C$. citratus oil had a bite at 3 hours into the experiment $(01.00$ hours), while one who used $6 \mathrm{ml}$ of oil experienced a bite only 1 hour 30 minutes later at 02:30; 
that is 4 hours 30 minutes from start of experiment. Of 30 mosquito landing attempts/bites experienced during the study, 21(70\%) were on the control subject; $8(27 \%)$ on the volunteer with $2 \mathrm{ml}$ of oil and $1(3 \%)$ on the volunteer with $6 \mathrm{ml}$ of oil (Table 1$)$.

\section{Repellent activity of lemon grass oil on mosquitoes in captivity}

Mosquitoes were observed to fly restlessly exhibiting frantic attempts to escape from the test box; and 13 (43\%) flew away from the oil-treated section (A) into the untreated section (B) of the insect box within the first minute of exposure. However, 17 (57\%) mosquitoes were knocked down, among which those that got in direct contact with the oil died within few minutes; but by the $18^{\text {th }}$ minute, $100 \%$ mortality was recorded in section A (Table 2).

Table 1: Time-dependent mosquito repellence by lemon grass oil on human subjects.

\section{Quantity of Number of Landing attempts/bites in time (Hours) \\ Oil applied (average values)}

\begin{tabular}{lllllllllll}
\hline & $\mathbf{0 . 5}$ & $\mathbf{1 . 0}$ & $\mathbf{1 . 5}$ & $\mathbf{2 . 0}$ & $\mathbf{2 . 5}$ & $\mathbf{3 . 0}$ & $\mathbf{3 . 5}$ & $\mathbf{4 . 0}$ & $\mathbf{4 . 5}$ & Total \\
\hline $\mathbf{2 m l}$ & 0 & 0 & 0 & 0 & 0 & 1 & 0 & 2 & 5 & 8 \\
$\mathbf{6 m l}$ & 0 & 0 & 0 & 0 & 0 & 0 & 0 & 0 & 1 & 1 \\
$\mathbf{0}($ control) & 3 & 3 & 2 & 4 & 2 & 2 & 2 & 1 & 2 & 21 \\
\hline Total & 3 & 3 & 2 & 4 & 2 & 3 & 0 & 3 & 8 & 30 \\
\hline
\end{tabular}

Source: Study result

Table 2: Effect of lemon grass oil on mosquitoes in captivity.

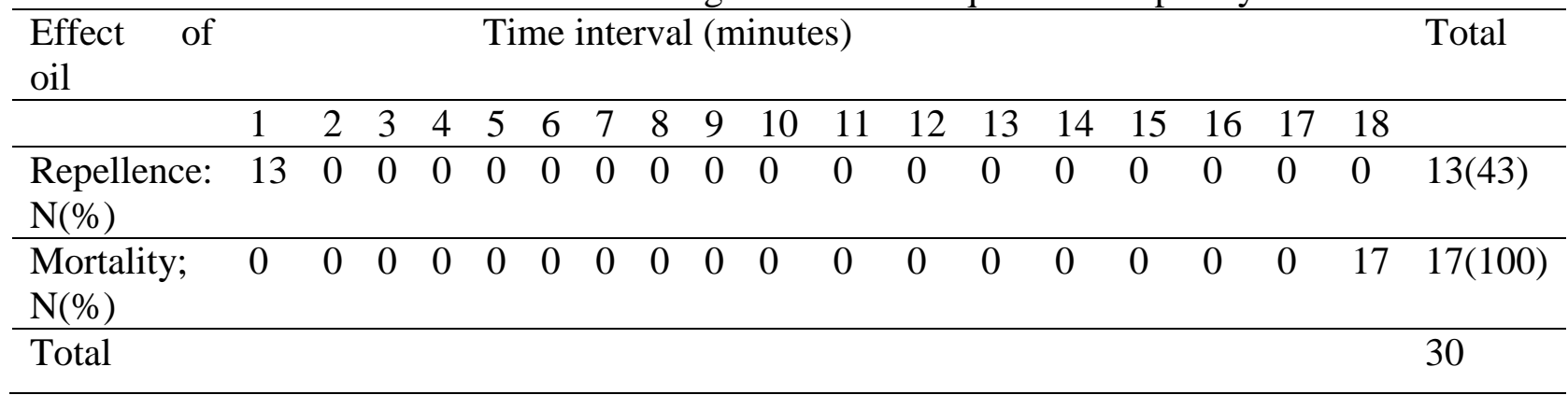

Source: Study result

\section{Discussion}

The study with human volunteers provided a real case situation for confirmatory observations on the repellent activity of lemon grass oil against mosquitoes. Mosquitoes usually make surreptitious landings on exposed skin to feed; reason why the wearing of protective clothing stands as a good measure of preventing man-vector contact, a primary method of malaria prevention [23]. Application of lemongrass oil prevented landing attempts and bites by mosquitoes; and this verifies already documented evidence that $C$. citratus extract is a potent mosquito repellent [21, [22].

However, the interval of protection is a matter of concern; in this study, lemon grass oil provided anti-mosquito protection for 3 hours after which landing attempts and bites were experienced. This observation would corroborate previous records of volatility of plants essential oils [11]; 
hence the duration of repellence might be undoubtedly connected with the concentration of oil. Using different volumes $(2 \mathrm{ml}$ and $6 \mathrm{ml})$ of the oil gave a suggestive result to consider that the intensity of oil could have relevance with its retention time on the skin and hence interval of protection. Only one bite was experienced by the volunteer who applied $6 \mathrm{ml}$ of oil and at 4 hours thirty minutes of experiment; by which time there were already 5 landing attempts/bites on volunteer with $2 \mathrm{ml}$ of oil. While the difference in volume is not equal to difference in concentration, it is assumable that at a higher level the essential oil would persist longer. This could also be explained from the result of laboratory test with mosquitoes in captivity. Mosquitoes which escaped from the oil-treated chamber of the insect box survived, while those that remained longer within the influence of the volatile oil were knocked down and eventually killed after 18 minutes. It is obvious that all the mosquitoes would have flown away from the source of discomfort (oil) if they were not in captivity.

Further, quantitative, studies would beam on the issue of interval of protection and provide useful guide for commercial production of lemon grass oil repellent for topical application against insect vectors. It would also provide reliable information for use of the extract in local mosquito prevention and control practices. Considering the high volatility, commercial formulation of plant-based repellents from essential oils would have to use fixatives to maintain longevity of their action [24].

The study with live mosquitoes also confirmed the insecticidal property of lemon grass oil, [25], [26], [27]. Assumed to be safer, compared with chemical based pesticides [11], [24], lemon grass oil would serve as a very effective natural product-based repellent and insecticide.

\section{Conclusion}

This study reports the repellent and insecticidal properties of Lemon grass oil against malaria mosquitoes in the study area; and contributes to the growing literature on safe bio-pesticides for disease control. While commercial formulations should be expected, local use of this and other plants essential oil is recommendable to prevent man-vector contact in local communities where transmission rates are high but healthcare interventions are lacking. While this study did not consider chemical composition and characterization of $C$. citratus essential oil, indeed, in-depth and continuous studies in the area of health and environmental safety of bio-pesticides are of immediate necessity in the midst of current global awareness for natural products.

\section{Acknowledgement}

We thank the management and student volunteers of Hall 2 male hostel, Cross River University of Technology, Calabar for cooperation and participation in the study, respectively.

\section{References}

[1] World Health Organization (1957). Malaria: Sixth report of the expert committee. Technical Report Series, No. 123, WHO, Geneva, Switzerland.

[2] World Health Organization (1993a). A global strategy for malaria control. WHO, Geneva, Switzerland. 
[3] World Health Organization (1993b). Implementation of the global malaria control strategy. WHO, Geneva, Switzerland.

[4] World Health Organization (1995).Vector control for malaria and other mosquitoe-borne diseases. WHO Technical Report Series 857, WHO, Geneva, Switzerland.

[5] Eldridge, B. (2000). Mosquitoes: Home and landscape, UC Pest management guidelines; the Regents of the University of California, www-ipm.uc.davis.edu.

[6] Baribwira, C., Kanyange, L. and Barutwanayo, M. (1997). The management of malaria and its vector: knowledge and practices in households in urban areas of Bujumbura (Burundi), Malar. Infect. Dis. Africa, 3:13-19.

[7] Ahorlu, C. K., Dunyo, S. K., Afari, E. A., Koram, K. A. and Nkrumah, F. K. (1997). Malariarelated beliefs and behavior in Southern Ghana: Implications for treatment, prevention and control. Trop. Med. Int. Hlt, 2(5): 488-499.

[8] Greenwood, B. (1999). What can the residents of malaria endemic countries do to protect themselves against malaria? Parassitologia, 41: 295-299.

[9] W. Van de Hoek, W., Konradsen, F., Dijkstra, D. S. Amerasinghe, P. H. and Amerasinghe, F. P. (1998). Risk factors for malaria: A micro-epidemiological study in a village in Sri Lanka. Trans. R. Soc. Trop. Med. Hyg., 92; 265-269.

[10] Lindsay, S. W.,Ewald, J. A.,Samung, Y.,Apiwathnasorn,C. and Nosten, F.(1998). Thanaka (Limonia acidissima) and DEET (Dimethyl benzamide) mixture as a mosquito repellent for use by Karen women. Med. Vet. Entomology, 12: 295-301.

[11] Bhupen, K., Somi, B. and Sharma, A. K. (2013). Plant essential oils as mosquito repellent: A Review. International Journal of Research and Development in Pharmacy and Life Sciences. 3(1): 741-747.

[12] L. Lopez-Carrillo, L., Torres-Arreola, L., Torres-Sanchez, L., Espinosa-Torres, F., Jimenez, C., Cebrian, M., Waliszewski, S. and Saldate, O. (1996). Is DDT use a public health problem in Mexico? Env. Hlth. Perspectives, 104(6): 584-588.

[13] Harrison, K. (1997). DDT a banned insecticide, www.chem.ox.ac.uk/mom/ddt/ddt.html.

[14] Mandavgane, S. A., Pattalwar, V. V., and Kalambe, A. R. (2005). Development of cow dung based herbal mosquito repellent. Natural Project Radiance. 4(4): 270-273.

[15] Fradin, M. S. and Day, F. J. (2002). Comparative efficacy of insect repellents against mosquito bites. New England J. Medicine, 347(1): 13-18.

[16] Environmental health Association of Nova Scotia (2003). The hazards of DEET. www.environmentalhealth.ca. Accessed December, 2016.

[17] Fishel, F. (2003). Pesticides and the environment. University of Missouri extension, www.extension.mission.edu. Accessed December, 2016.

[18] National Pesticide Information Center (2008). DEET General fact sheet, www.npic.orst.edu. Accessed December, 2016.

[19] Bakkali, F., Averbeck, S., Averbeck, D. and Idaomar, M. (2008). Biological effects of essential oils. Food and Chemical Toxicology, 46(2): 446-475.

[20] Etta, H. E., Ukpong, I. G., Iboh, C. I. and Momoh, E. N. (2016). Preliminary investigations of the insecticidal effect of Ocimum Gratissimum (L) on adult Anopheles mosquitoes. International Journal of health and Pharmaceutical Research, 2(1): 66-71.

[21] Baldacchino, F., Tramut, C., Salem, A., Lienard, E., Deletre, E., Franc, M., Martin, T., Duvallet, G. and Jay-Robert, P. (2013). The repellency of Lemongrass oil against stable flies, tested using video tracking, Parasite, 20:21.

[22] Prabhakar, K., Kinnera, K., Priya, K. K. and Peele,K. A. (2013). Investigation of the repellence activity of Bio-out, A natural mosquito repellent. International Journal of Life Sciences, Biotechnology and Pharma Research, 2:3.

[23] Ichhpujani, R. L. and Bhatia, R. (2002). Medical parasitology (New Delhi, Jaypee brothers Medical Publishers, pp 309. 
[24] Maia, M. F. and Moore, S. J. (2011). Plant-based insect repellents: a review of their efficacy, development and testing. Malar. J., 10(1): S11.

[25] Kabera, J., Gasogo, A., Uwamariya, A., Ugirinshuti, V. and Nyetera, P. (2011). Insecticidal effects of essential oils of Pelargonium graveolens and Cymbopogon citratus on Sitophilus zeamais (Motsch.). African Journal of Food Science, 5(6): 366-375.

[26] Bossou, A. D., Mangelinckx, S., Yedomonhan, H., Boko, P. M., Akogbeto, M. C., De-Kimpe, N., Avlessi, F. and Sohounhloue, D. C. K. (2013). Chemical composition and insecticidal activity of plant essential oils from Benin against Anopheles gambiae (Giles). Parasites and vectors, 6: 337.

[27] Pinto, Z. T., Sanchez, F. F., Ramos, A., Amaral, A. C. F., Ferreira, J. L., Escalona-Arranz, J. C. and Queiroz, M. M. D.(2015). Chemical composition and insecticidal activity of Cymbopogon citratus essential oil from Cuba and Brazil against housefly. Braz. J. Vet. Parasitol., Jaboticabal, 24(1): 36-44.

*Corresponding author.

E-mail address: iniodugeorge@ yahoo.com 